\title{
Are differences in hydrocarbon profiles able to mediate strain recognition in German cockroaches (Dictyoptera: Blattellidae)?
}

\author{
COLETte RIVAULT ${ }^{*}$, AnN CLOAREC ${ }^{1}$ and LEAm SRENG ${ }^{2}$ \\ ${ }^{1}$ CNRS UMR 6552, Université de Rennes I, Campus de Beaulieu, 35042 Rennes Cedex, France \\ ${ }^{2}$ CNRS UPR 9024, LNB, Laboratoire de Neurobiologie et Communication Chimique, 31 Chemin Joseph Aiguier, 13402 Marseille \\ Cedex 20, France
}

Key words. Cuticular hydrocarbons, strain recognition, Blattella germanica

\begin{abstract}
Previous behavioural tests indicated that strain recognition and aggregation behaviour could be induced by cuticular hydrocarbons. The aim of this study was to document and to compare cuticular hydrocarbon profiles between different strains of Blattella GERMANICA (L.) (Dictyoptera: Blattellidae) and to relate variations in the general profile of cuticular hydrocarbons with strain discrimination during behavioural tests. Profiles of different strains were remarkably similar qualitatively but presented slight quantitative differences over the 25 identified components. Important differences were observed in dimethylalkane components and these allowed separation of the strains into two groups using multivariate methods. Although we were not able to demonstrate a relationship between strain discrimination ability and differences in cuticular hydrocarbon profiles, we assumed that cuticular hydrocarbons could play two major roles in $B$. germanica strains. Less variable hydrocarbon profiles could play a role in species recognition and aggregation behaviour and the more variable part could play a role in strain discrimination.
\end{abstract}

\section{INTRODUCTION}

Cuticular lipids comprise a thin layer of polar and apolar material on the outer surface of insect cuticles. Their primary functions are to prevent desiccation, to regulate cuticular permeability and to prevent pathogenic invasion (de Renobales et al., 1991). A growing area of interest in insect studies concerns the different roles of cuticular hydrocarbons, which can range from physiological functions, semiochemical functions and behavioural roles to taxonomic and systematic use. Furthermore, they act as intra- and interspecific signals for insects (Howard, 1993). Chemical communication based on cuticular hydrocarbons with no apparent glandular origin is a frequent phenomenon among all eusocial insects. In insects, these components act as sex pheromones (Schal et al., 1990a, b), aggregation pheromones (Rivault et al., 1998), inter- and intra-species recognition signals and population and caste recognition signals (termites: Brown et al., 1996; Bagnères et al., 1991; ants: Provost et al., 1993; Bonavita-Cougourdan et al., 1989; Nowbahari et al., 1990), The use of cuticular lipids in chemosystematics to assess how insects are related is also a valuable tool (Howard, 1993). Large variability in insect cuticular hydrocarbons occurs at many levels, from the individual to the population level. Furthermore, seasonal differences within a given species have been reported (Clément, 1986; Bagnères et al., 1990; Dahbi \& Lenoir, 1998).

In the German cockroach, Blattella germanica (L.), (Dictyoptera: Blattellidae), cuticular hydrocarbons consist of a complex mixture of apolar compounds which contain n-alkanes and mono- and dimethylalkanes (Augusty- nowicz et al., 1987; Carlson \& Brenner, 1988; Jurenka et al., 1989; Rivault et a1., 1998). Our previous results showed that cuticular hydrocarbons operate as an aggregation pheromone and that in choice tests, young larvae select filter papers conditioned by cuticular hydrocarbons as resting areas (Rivault et al., 1998). Furthermore, in behavioural choice tests they are able to discriminate their strain odour, deposited on filter papers by general body contact (Rivault \& Cloarec, 1998).

We hypothesized that differences in cuticular hydrocarbon profiles between strains could play a part in strain discrimination in $B$. germanica. This species is a presocial insect which forms large aggregates including all age classes. Maintenance of aggregates involves social recognition and social interactions (Rivault \& Cloarec, 1998, 1999). This urban cockroach with a world-wide distribution forms a metapopulation with random contacts between populations, which either become extinct or explode, according to local environmental conditions (Rivault \& Cloarec, 1995). These local populations, which we called "strains", are inter-fertile and present no behavioural exclusion or strain closure comparable to eusocial colony closure. However, geographical and/or temporal distance between some strains could lead to slight modifications in cuticular hydrocarbon composition and induce the start of population differentiation.

The aim of this study was to document and to compare cuticular hydrocarbon profiles of different strains of $B$. germanica collected from different locations and to test whether variations in the general profile of cuticular hydrocarbons could be related to strain recognition abilities.

\footnotetext{
* Corresponding author. E-mail: colette.rivault@univ-rennes1.fr; fax: (33) 02232369 27; tel: (33) 0223236931.
} 


\section{MATERIALS AND METHODS}

\section{Blattella germanica strains}

Adult cockroaches were collected from different locations and each strain was kept in an isolated cage in the laboratory after capture, under strictly identical conditions (in the same climatized room, in the same type of cage, fed the same diet, reared at similar densities). Therefore, environmental effects were minimized and differences between strains were not related to environmental differences.

Our reference strain called R1 was compared with all the other strains (R2, R3, R4, R5, R6, R7, S1 and S2). R2 and R3 came from the same building as $\mathrm{R} 1$, our reference strain. $\mathrm{R} 1$ was bred from cockroaches collected in 1987 and maintained in the laboratory since then. R2 and R3 were collected in February 1997 and July 1997, respectively. These three strains came from the same initial population which was continuously surveyed in this well-isolated building. Although R1, R2 and R3 may have undergone genetic drift during this ten-year isolation, they belong to the same initial genetic pool, and were obviously more closely related genetically to each other because they shared the same ancestors, than to members of the other strains.

R4, R5, R6 and R7 came from different buildings in Rennes (France). S1 and S2 came from different buildings in Sčte (France), a town $800 \mathrm{~km}$ from Rennes. Relatedness between all these strains or duration of isolation of different strains are unknown.

\section{Bioassays}

Behavioural test conditions were similar to those described by Rivault and Cloarec (1998). A group of 20 first instar larvae was placed in a petri dish $(140 \mathrm{~mm}$ in diameter and $20 \mathrm{~mm}$ high) and presented with a choice between two filter papers $(60 \times 15 \mathrm{~mm}$, folded in 4 to form a "W"). The choice was always between one paper conditioned by larvae of the strain tested and a second paper conditioned by larvae of another strain. Paper conditioning was achieved by placing 15 papers in a dish with 400 normally fed and watered first instar larvae for four days. During this time, each paper was conditioned by contamination with general body contact of many larvae. This contamination method representing global strain odour, was chosen to mimic natural shelter conditions where many individuals are gathered. Previous results allowed us to conclude that only the presence of cuticular hydrocarbon extracts was able to induced aggregation in behavioural tests (Rivault et al, 1998).

Each test lasted $24 \mathrm{~h}$ and was carried out under a 12L : 12D light dark cycle at $25^{\circ} \mathrm{C}$. Tests were prepared during the rest phase, which occurs during the light period of the cockroach photoperiod. Larvae aggregate when resting, therefore $24 \mathrm{~h}$ later, during the following rest period and after one active period during the dark phase to allow exploration of the dish, the positions of the larvae in the petri dish were recorded. There were three possible positions for the larvae in the dish: on either conditioned paper or elsewhere in the dish. For each series of experiments, we calculated the mean number of animals per test observed in each of the three different positions.

\section{Cuticular hydrocarbon analysis}

To prepare each chemical extract, 15 sixth instar larvae were used. As aggregation odour was produced and perceived at all developmental stages (Rivault \& Cloarec, 1998), extracts were made with $6^{\text {th }}$ instar larvae which were easier to handle than large groups of $1^{\text {st }}$ instars used in behavioural essays. Three different solvents were used to extract cuticular hydrocarbons: dichloromethane, methanol and pentane. Although methanol is a poor solvent for hydrocarbons, it was used for comparison purposes.
To prepare each extract, larvae were anaesthetized with $\mathrm{CO}_{2}$ and immersed in $1.5 \mathrm{ml}$ of pentane, methanol, or dichloromethane for $5 \mathrm{~min}$, and then the insects were removed from the solvent. Two samples of each strain ( S1a, S1b, S2a, S2b, R2a, R2b, R3a, R3b, R4a, R4b, R5a, R5b, R6a, R6b, R7a, R7b) and five samples of the reference strain (R1a, R1b, R1c, R1d, R1e) were assayed.

As gas chromatography profiles of extracts before and after passing through a silica gel microcolumn gave the same peak patterns (Rivault et al., 1998), this procedure was no longer applied. The extracts were concentrated under nitrogen flow to a volume of $50 \mu 1$ prior to analysis. A $2 \mu 1$ sample was analyzed by gas chromatography (GC) on a Delsi $200 \mathrm{DN}$ coupled to an Enica 31 integrator and equipped with a flame ionization detector (FID), a CPsil 5 column ( $25 \mathrm{~m} \times 0.25 \mathrm{~mm} \mathrm{ID})$, and a split-splitless injector (splitless mode $15 \mathrm{sec}$.). Helium was the carrier gas. The temperature program started at $90^{\circ}$ for $3 \mathrm{~min}$, increased to $230^{\circ}$ at $15 \% \mathrm{~min}$ and then to $320^{\circ}$ at $5^{\circ} / \mathrm{min}$ (isotherm time $10 \mathrm{~min}$ ).

The quantification of each component (percentage of the total peak surface) was calculated by taking into account a response coefficient $\mathrm{K}=(0.042 \times \mathrm{nC})+0.11$, for the flame ionization detector (FID) where $\mathrm{nC}$ is the number of carbon atoms in a hydrocarbon (Bagnères et al., 1991).

\section{Statistical analyses}

A multivariate analysis (factorial correspondence analysis, FCA, Benzecri, 1973) was computed on relative amounts of cuticular hydrocarbon components in relation to strain samples. Factorial correspondance analysis is a descriptive method which gives the best representation of a cloud of data points along several sets of axes determined by correlational structure of the data with minimal information loss and without prior hypothesis (Greenacre, 1984; Fenelon, 1981). This FCA was completed by a Hierarchical Cluster Analysis performed on the coordinates of the data points on the first two axes of the FCA analysis which gives the degree of relatedness of the data points inside the cloud (Jambu \& Lebeaux, 1983).

Significance of differences between means was estimated by t-tests.

\section{RESULTS}

\section{Cuticular hydrocarbon analysis Extract comparisons}

The most important feature of the cuticular hydrocarbon patterns of all the $B$. germanica strains sampled from different locations and from different buildings was their remarkable similarity across strains. Although minor quantitative differences existed between strains, which could be separated by a FCA, the overall picture was one of consistency.

Twenty five components (Fig. 1, Table 1) were identified in all the strains tested: three n-alkanes, 13 monomethylalkanes and nine dimethylalkanes (Rivault et al., 1998). The proportions of the different hydrocarbon components obtained in methanol suggested important quantitative differences to those obtained in pentane or dichloromethane. These two solvents extracted similar quantities of different components (Fig. 2). All dimethylalkanes were completely extracted in methanol, whereas two monomethylalkanes: 3-methylheptacosane (e), 5-methylnonacosane (o), 3-methylnonacosane (q), and three saturated alkanes: $n$-heptacosane (a), 
TABLE 1. Cuticular hydrocarbons of Blattella germanica (L.).

\begin{tabular}{|c|c|c|c|c|}
\hline Peak & Compounds-fragment & MW & TC & $\mathrm{CI}\left(\mathrm{CH}_{4}\right)$ \\
\hline $1-\mathbf{a}$ & $n$-Heptacosane & 380 & 27 & 379 \\
\hline \multirow[t]{2}{*}{$2-\mathbf{b}$} & 9-,11- and 13-Methylheptacosane & 394 & 28 & 393 \\
\hline & $140 / 141,280 / 281,168 / 169,252 / 253,196 / 197,224 / 225$ & & & \\
\hline $3-\mathbf{c}$ & 5-Methylheptacosane 308, 337 & 394 & 28 & 393 \\
\hline \multirow[t]{3}{*}{$4-\mathbf{d}$} & 11, 15-Dimethylheptacosane & 408 & 29 & 407 \\
\hline & $168 / 169,196 / 197,239,267$ & & & \\
\hline & 3-Methylheptacosane & 394 & 28 & 393 \\
\hline \multirow[t]{2}{*}{$6-\mathbf{f}$} & 5,9- and 5, 11-Dimethylhaptacosane & 408 & 29 & 407 \\
\hline & $155,280 / 281,351,379,183,252 / 253,351,379$ & & & \\
\hline $7-\mathbf{g}$ & n-Octasone & 394 & 28 & 393 \\
\hline \multirow[t]{2}{*}{$8-\mathbf{h}$} & 3, 11- and 3,9-Dimethylheptacosane & 408 & 29 & 407 \\
\hline & $155,280 / 281,379,183,252 / 253,379$ & & & \\
\hline \multirow[t]{2}{*}{$9-\mathbf{i}$} & 12- and 14-Methyloctasone & 408 & 29 & 407 \\
\hline & $182 / 183,252 / 253,210 / 211,224 / 225$ & & & \\
\hline $10-\mathbf{j}$ & 2-Methyloctasone & 408 & 29 & 407 \\
\hline $11-\mathbf{k}$ & 4-Methyloctasone $365,336 / 337$ & 408 & 29 & 407 \\
\hline $12-\mathbf{I}$ & $n$-Nonacosane & 408 & 29 & 407 \\
\hline \multirow[t]{2}{*}{$13-\mathbf{m}$} & 9-, 11-, 13- and 15-Methylnonacosane & 422 & 30 & 421 \\
\hline & $140 / 141,308 / 309,168 / 169,280 / 281,196 / 197,252 / 253$ & & & \\
\hline \multirow[t]{2}{*}{$14-\mathbf{n}$} & 7-Methylnonacosane & 422 & 30 & 421 \\
\hline & $112 / 113,336 / 337,407$ & & & \\
\hline $15-0$ & 5-Methylnonacosane 336, 337, 365 & 422 & 30 & 421 \\
\hline \multirow[t]{2}{*}{$16-\mathbf{p}$} & 11,15- and 13,17-Dimethylnonacosane & 436 & 31 & 435 \\
\hline & $168 / 169,224 / 225,239,295,196 / 197,267$ & & & \\
\hline $17-\mathbf{q}$ & 3-Methylnonacosane $364,365,393$ & 422 & 30 & 421 \\
\hline \multirow[t]{2}{*}{$18-\mathbf{r}$} & 5,9- and 5,11-Dimethylnonacosane & 436 & 31 & 435 \\
\hline & $155,308 / 309,351,379,183,280 / 281,351,379,211,252 / 253,351,379$ & & & \\
\hline \multirow[t]{2}{*}{$19-\mathbf{s}$} & 3, 7-, 3,9- and 3, 11-Dimethylnonacosane & 436 & 31 & 435 \\
\hline & $127,336 / 337,379,407,155,308 / 309,379,407,183,280 / 281,379,407$ & & & \\
\hline \multirow[t]{2}{*}{$20-\mathbf{t}$} & 11-, 13-, and 15-Methyltriacontane & 436 & 31 & 435 \\
\hline & $168 / 169,294 / 295,196 / 197,266 / 267,224 / 225,238 / 239$ & & & \\
\hline \multirow[t]{2}{*}{$21-\mathbf{u}$} & 4, 8- and 4, 10-Dimethyltriacontane & 450 & 32 & 449 \\
\hline & $141,169,308 / 309,336 / 337$ & & & \\
\hline \multirow[t]{2}{*}{$22-\mathbf{v}$} & 11-, 13-, and 15-Methylhentriacontane & 450 & 32 & 449 \\
\hline & $168,169,308 / 309,196 / 197,280 / 281,224 / 225,253 / 253$ & & & \\
\hline \multirow[t]{2}{*}{$23-\mathbf{w}$} & 13,17- and 11,15-Dimethylhentriacontane & 464 & 33 & 463 \\
\hline & $168 / 169,239,252 / 253,323,196 / 197,224,267,295$ & & & \\
\hline \multirow[t]{2}{*}{$24-\mathbf{x}$} & 5,9-and 5, 11-Dimethylhentriacontane & 464 & 33 & 463 \\
\hline & $84 / 85,155,336 / 337,407,435,183,308 / 309,407,435$ & & & \\
\hline \multirow[t]{2}{*}{$25-\mathbf{y}$} & 10 and 12-Methyldotriacontane & 464 & 33 & 463 \\
\hline & $154 / 155,182 / 183,308 / 309,336 / 337$ & & & \\
\hline
\end{tabular}

25 peaks with letters used in Fig. 3 and in text; MW: Molecular weight; TC: Total carbon; $\mathrm{CI}\left(\mathrm{CH}_{4}\right)$ : Chemical ionisation.

$n$-octacosane $(\mathrm{g}), n$-nonacosane (l) were less abundant (t-test, all $\mathrm{P}<0.05$ ) when extracted in methanol than in pentane or in dichloromethane (Fig. 2). As the methanol extracts were much less efficient in inducing aggregation than the pentane or dichloromethane extracts, the six "missing" components in the methanol extracts were assumed to be responsible for the gregarious behaviour observed (Rivault et al., 1998).

In addition, our present results showed that these six "missing" components (a, e, g, 1, o and q) in methanol extracts were consistently the same for all the $B$. germanica strains tested. 




Fig. 1. Gas chromatogram of cuticular hydrocarbons from extracts of larvae from $\mathrm{P}$ strain in dichloromethane. 25 peaks are lettered (a-y) according to the components identified by GC-MS given in Rivault et al. (1998). This typical sample is lettered P1 in Fig. 3.

\section{Strain differences}

A multivariate analysis (FCA) completed by a Hierarchical Cluster Analysis performed on the co-ordinates of the data on the first two axes of the FCA, revealed strain differences in cuticular hydrocarbon profiles. As some cuticular hydrocarbon components bore nearly all the contribution weight on the axes of the analysis and were responsible for separating the strains into two groups, the FCA analysis was performed using dimethylalkane components as variables and the rest of the components (n-alkane and monomethylalkane components) as supplementary variables (Benzecri, 1973). The first three factorial axes accounted for $92 \%$ (dichloromethane extracts), $89 \%$ (pentane extracts) and 94\% (methanol extracts) of the total variability. The Hierarchical Cluster Analysis allowed us to identify two main groups of strains, as represented on the cloud of the data points based on the first two axes of the FCA. Group 1 included S1, S2, R2, R3, R5, and R6 strains and group 2 included R1, R4, and R7 strains (Fig. 3). Whatever the extracting solvent, (dichloromethane, pentane or methanol) the cuticular hydrocarbon profiles separated the strains into the same two groups. The relative quantities of most of the dimethylalkane components differed significantly between the two groups of strains ( $t$ tests, $p<0.05)$. In group 1 , components $\mathrm{d}, \mathrm{f}, \mathrm{h}$ and $\mathrm{w}$ were in larger proportions than in group 2, whereas components $r, s$ and $u$ were in smaller proportions. Only two dimethylalkane components, ( $p$ and $\mathrm{x}$ ), had similar proportions in the two groups (Fig. 4). Few differences were observed in saturated monometh- ylalkanes and n-alkanes between the two groups (Fig. 4). The centres of gravity of the components a, e, g, l, o and q, ("missing" in the methanol extracts) were projected very near to the origin of axes 1 and 2, indicating that they play insignificant roles in separating the two groups of strains (Fig. 3).

Two groups of strains were defined in relation to the relative amounts of dimethylalkanes in their cuticular hydrocarbon profiles. As extracts were obtained with several individuals rather than individual cuticular hydrocarbon profiles, they represent global variations between strains that can be compared to the bioassays.

\section{Strain differentiation}

The Cluster Analysis revealed that all R1 samples (R1a, R1b, R1c, R1d, R1e) were in Group 2 (Fig. 3). All R2 and R3 samples, collected 6 months apart in the same building, were in Group 1. As R1, R2 and R3 strains were collected in the same building, they were supposed to be more closely related genetically to each other than to other strains. Our results showed that ten years isolation appeared long enough to induce significant differences in hydrocarbon profiles.

Strains from Sète with no known genetic relatedness were both in Group 1. Strains from Rennes were separated in Groups 1 and 2 (Fig. 3).

Furthermore, variability between $\mathrm{R} 1$ extracts (R1a, R1b, R1c, R1d, R1e) was as important as that observed between extracts of strains well separated geographically 


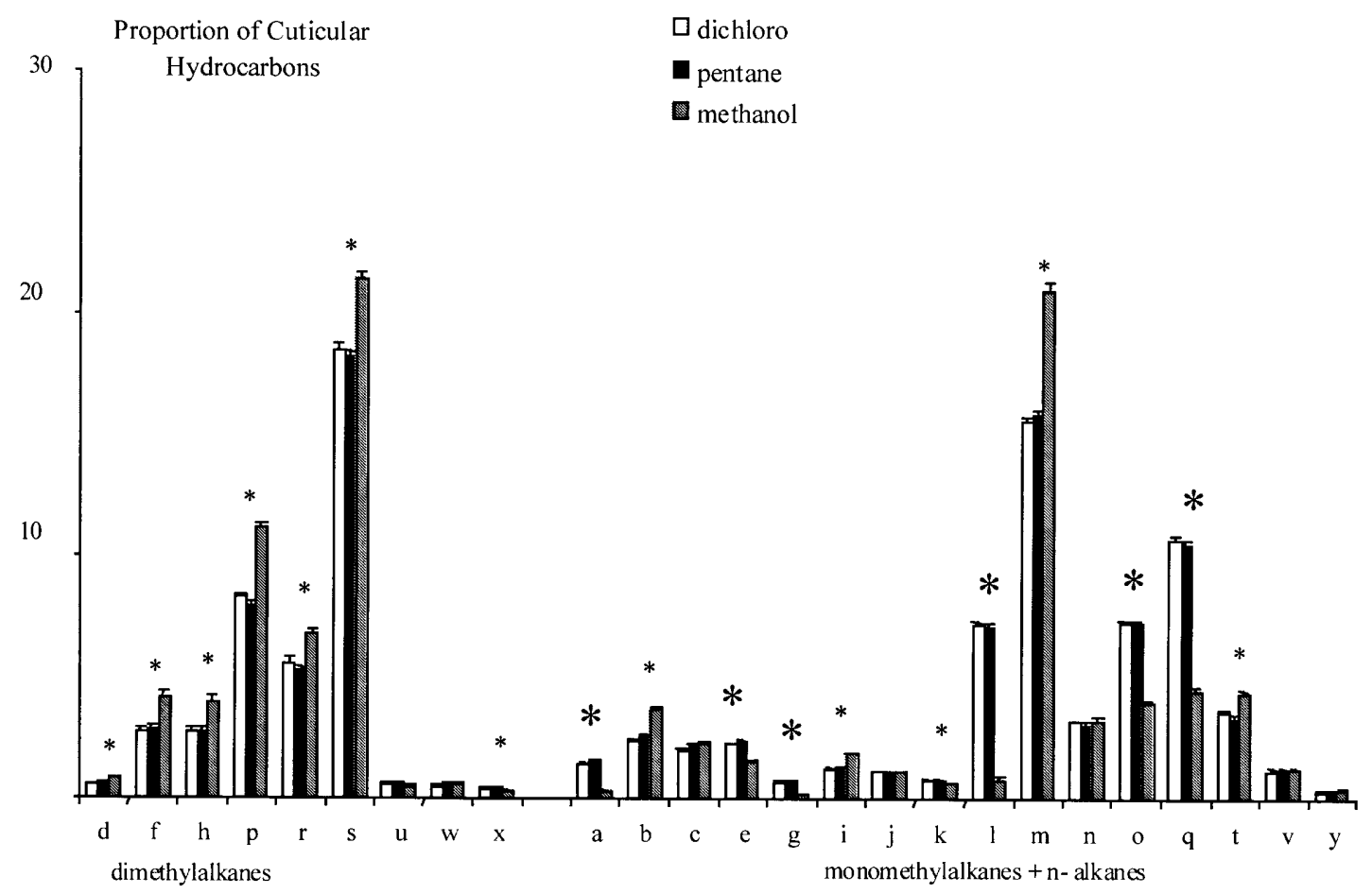

Fig. 2. Mean $(+\mathrm{SE})$ proportions of 25 cuticular hydrocarbon components (a-y) for all strains tested, extracted in three solvents (dichloromethane, methanol, pentane). a, g, 1, o and q were less extracted in methanol. Small asterisk: t-test, proportions in methanol were significantly larger than in the two other solvents. Large asterisk: t-test, proportions in methanol were significantly smaller than in the two other solvents.

and genetically (variance comparison, $\mathrm{F}_{11}^{4}=5.67, \mathrm{p}>$ $0.05)$.

Ten years seemed to be long enough to induce differences in cuticular hydrocarbon profiles and to separate strains (R1, R2 and R3) collected in the same building into two groups. On the other hand, cuticular hydrocarbon profiles of strains separated geographically and genetically for much longer periods presented more similarities. The observed variability in cuticular hydrocarbon profiles seems to be the consequence of the combination of three factors: time of separation, geographical distance and genetic relatedness.

\section{Behavioural bioassays}

Groups of larvae from different strains were involved in choice tests between paper conditioned by their own strain odour and paper conditioned by an unfamiliar strain odour (see Rivault and Cloarec, 1998, for more detail). Because papers had to be heavily conditioned to induce a good behavioural response, the odours came from contact with many larvae. Therefore, reaction to this odour represents a reaction to the general odour of that strain. Cockroaches from S1, S2, R4, R5, R6, R7 and R1 strains were able to distinguish between their own odour and that of an unfamiliar strain (t-test, $\mathrm{p}<0.05$ ) (Table 2). Although R1, R4 and R7 strains were in the same FCA group, cockroaches from these strains were able to discriminate amongst their odours (Fig. 3). On the contrary, R2, R3 and R1 larvae were not able to discriminate amongst their odours (Table 2, t-test, $\mathrm{p}>0.05$ ). R1, R2 and R3 larvae did not aggregate preferentially on the paper conditioned by their own odour. The fact that they aggregated on either paper seemed to indicate that they were not able to discriminate between the two papers and thereby between the two odours. As the R1, R2 and R3 strains were collected initially in the same building, they were more closely genetically related than any of the other test strains. Although they exhibited important differences in hydrocarbon profiles as shown by the FCA, they did not discriminate between each other.

It must be stressed that the separation of these strains into two groups in relation to cuticular hydrocarbon profiles is not correlated with their ability to distinguish strain odours. Cockroaches from strains with only small quantitative differences in a few cuticular hydrocarbon components are still able to discriminate between odours deposited on the filter papers. However, larger differences in cuticular hydrocarbon profiles do not always induce strain discrimination. Strain discrimination is probably due to multiple factors and cuticular hydrocarbons may not be the only cue.

\section{DISCUSSION}

Cuticular hydrocarbon profiles of different strains of $B$. germanica cockroaches were remarkably similar qualitatively but presented slight quantitative differences over the 25 identified components. Six components: n-heptacosane (a), 3-methylheptacosane (e), n-octacosane (g), n-nonacosane (l), 5-methylnonacosane (o), 3-methylnonacosane (q), were, for all strains, consistently less concentrated in methanol extractions than in dichlo- 
TABLE 2. Results of choice tests between two conditioned papers: own odour and unfamiliar strain odour.

R1 groups of 20 larvae were presented a choice between their own odour and the odour of an unfamiliar strain (S1, S2, R2, R3, R4, R5, R6 or R7). Symmetrically, groups of 20 larvae from strains : S1, S2, R2, R3, R4, R5, R6 or R7 were presented a choice between their own odour and R1 strain odour. As symmetrical paired tests were not significantly different (t-test, $p<0.05)$, data per pairs were pooled. When R1 larvae discriminated, larvae of other strains were also able to do it.

\begin{tabular}{|c|c|c|c|c|c|c|c|c|}
\hline \multirow[b]{4}{*}{ group 1} & \multirow{3}{*}{ Tested pairs } & \multirow{3}{*}{ Number of tests } & \multicolumn{6}{|c|}{ Number of cockroaches on: } \\
\hline & & & \multicolumn{2}{|c|}{ Unfamiliar strain odour } & \multicolumn{2}{|c|}{ Own odour } & \multicolumn{2}{|c|}{ Dish } \\
\hline & & & Mean & $\mathrm{SE}$ & Mean & $\mathrm{SE}$ & Mean & $\mathrm{SE}$ \\
\hline & $\mathrm{S} 2 / \mathrm{R} 1$ & 67 & $8.28 *$ & 1.01 & $10.86^{*}$ & 1.02 & 0.85 & 0.29 \\
\hline \multirow[t]{5}{*}{$(\mathrm{FCA})$} & $\mathrm{S} 1 / \mathrm{R} 1$ & 48 & $5.52 *$ & 1.14 & $11.93^{*}$ & 1.14 & 2.54 & 0.54 \\
\hline & $\mathrm{R} 5$ / R1 & 46 & $7.67 *$ & 1.27 & $11.26^{*}$ & 1.28 & 1.06 & 0.39 \\
\hline & $\mathrm{R} 6$ / R1 & 94 & $5.84^{*}$ & 0.78 & $12.19^{*}$ & 0.86 & 1.96 & 0.50 \\
\hline & $\mathrm{R} 2 / \mathrm{R} 1$ & 66 & 7.46 & 1.00 & 7.95 & 1.00 & 4.57 & 0.90 \\
\hline & $\mathrm{R} 3$ / R1 & 75 & 6.85 & 0.89 & 8.93 & 0.97 & 4.21 & 0.87 \\
\hline group 2 & $\mathrm{R} 4$ / R1 & 41 & $7.87^{*}$ & 1.34 & $10.80^{*}$ & 1.26 & 1.31 & 0.35 \\
\hline (FCA) & $\mathrm{R} 7 / \mathrm{R} 1$ & 58 & $4.94 *$ & 0.88 & $12.98^{*}$ & 1.02 & 2.06 & 0.39 \\
\hline
\end{tabular}

*significantly different values (t-test, $\mathrm{p}<0.05$ )

romethane or in pentane. As the methanol extracts were less efficient in inducing aggregation behaviour, these data support our previous results which suggested that these "missing" components might be responsible for aggregation behaviour between individuals of the species B. germanica (Rivault et al., 1998). Furthermore these components play no part in separating groups of strains in relation to cuticular hydrocarbons profiles. These components can be interpreted as some species-specific invariants. $n$-heptacosane is present in the cuticular hydrocarbon profiles of five Periplaneta spp., Blatta orientalis and Leucophaea maderae and $n$-nonacosane is present in three Periplaneta spp. (Augustynowicz et al., 1987). The three other components (n-octacosane, 5-methylnonacosane and 3-methylnonacosane) were found in B. germanica and $B$. asahinai but were absent in $B$. vaga (Carlson \& Brenner, 1988). Cuticular hydrocarbon profiles differ between $B$. germanica and $B$. asahinai (Blattellidae: Blattellinae), as they do not present the same peaks or the same proportions of components,

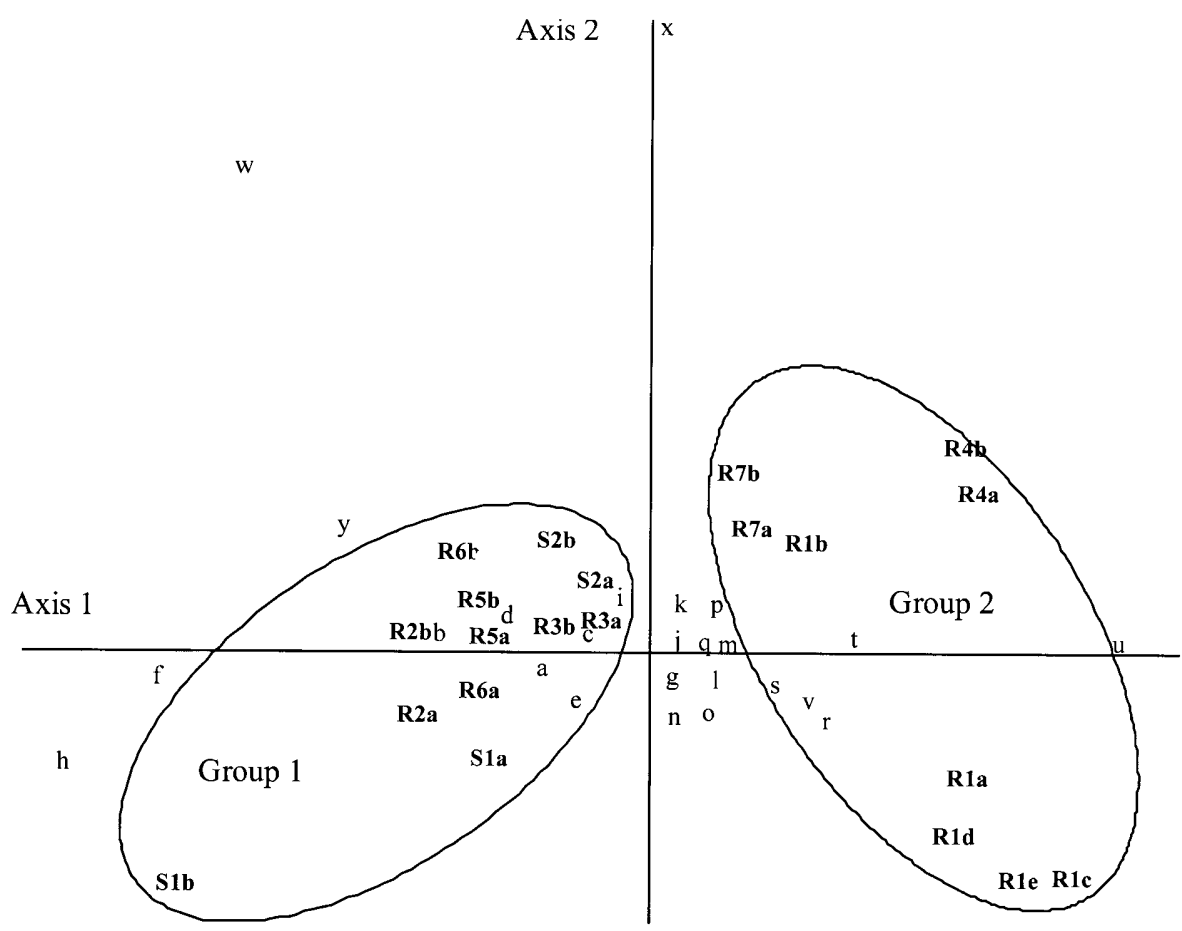

Fig 3. Projection of relative quantities of 25 cuticular hydrocarbon components extracted in dichloromethane in relation to nine cockroach strains on the plane defined by axes 1 (vertical) and 2 (horizontal) of the FCA. The ovals delineate strain groups 1 and 2 defined by the Cluster Analysis made on the co-ordinates of the data points on the first two FCA axes.

Legend: a-y. Cuticular hydrocarbon components. R1a, R1b, R1c, R1d, R1e R4a, R4b, R7a and R7b: Strain samples in Group 2; S1a, S1b, S2a, S2b, R2a, R2b, R3a, R3b, R5a, R5b, R6a and R6b: Strain samples in Group 1 (see text). 


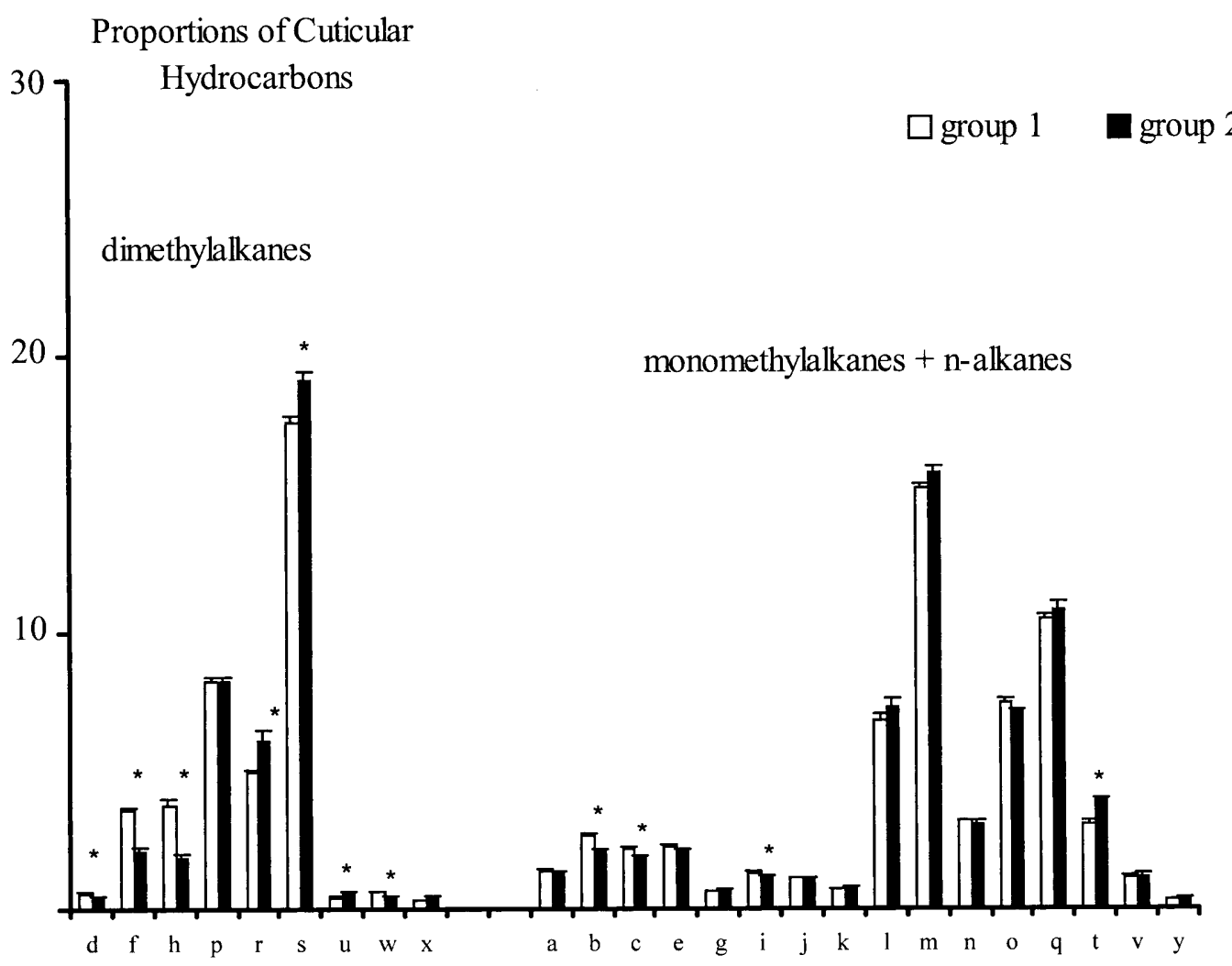

Fig. 4. Comparison of mean ( $+\mathrm{SE})$ proportions of 25 cuticular hydrocarbon components extracted in dichloromethane between the two FCA groups of strains. * : significant difference (t test, $\mathrm{p}<0.05$ ).

but they resemble each other more than they resemble profiles for Periplaneta americana or Blatta orientalis (Blattidae: Blattinae). Furthermore the differences between $B$. germanica strains presented by Carlson \& Brenner (1988) resemble the differences we found between our strains. These components are common to several cockroach species that are also urban species, which means that recognition of the specific aggregation pheromone must be based on discerning small quantitative differences. However, the fact that cuticular hydrocarbon profiles have already been used by several groups for species identification (Carlson \& Brenner, 1988; de Renobales et al., 1991) does not mean that these components are relevant per se for insect communication systems. Nevertheless the quantitative stability of the six components (a, e, g, 1, o and q) in all strains and the absence of behavioural response with methanol extracts led us to assume that they play an important part in species recognition as well as in aggregation behaviour in $B$. germanica.

Our results enabled us to separate the strains into two groups based on the most important differences in hydrocarbon profiles. The greatest differences were observed for the dimethylalkane components $(\mathrm{d}, \mathrm{f}, \mathrm{h}, \mathrm{p}, \mathrm{r}, \mathrm{s}, \mathrm{u}$ w, $\mathrm{x}$ ), whereas the other components (n-alkanes and the monomethylalkanes) showed no important differences between the two groups. Quantitative differences in cuticular hydrocarbons play a role in nestmate recognition in Reticulitermes termites and Camponotus ants, especially dimethylalkanes which differ significantly in pro- portion between societies where aggression is high (Bonavita-Cougourdan et al., 1987; Vauchot et al., 1996). Even though differences based on quantitative variations of dimethylalkane components could be observed in $B$. germanica, we were not able to relate these differences with strain discrimination. Before definitely rejecting our initial hypothesis, a larger number of strains must be tested. Furthermore, these differences were not directly related to geographical origin, temporal separation or genetic relatedness. Gene flow and founder effect are major factors in genetic structure of German cockroach populations. The fact that the genetic structure of $B$. germanica populations points to differentiation on a local scale but not on a large geographical scale (Cloarec et al., 1999 ) is in agreement with variation in cuticular hydrocarbon profiles. $B$. germanica forms a large metapopulation with a world-wide distribution. Strain discrimination behaviour in $B$. germanica and the quantitative variations in cuticular hydrocarbon composition are very similar to those reported for the spider Anelosimus eximius. In this spider, variation in cuticular hydrocarbon profiles does not lead to group closure and the observed differences are not directly linked to dispersion of the colony. They vary independently and seem to be the result of the genetic background of the colony (Pasquet et al., 1997). Brown et al. (1996) came to the same conclusion concerning intercolony variation in the termite Drepanotermes perniger, where differences were no greater than those between individuals of one colony. 
We assume that cuticular hydrocarbons could play two major roles in $B$. germanica strains. The less variable part of the cuticular hydrocarbon profiles (n-alkanes and monomethylalkanes), in particular the six components, a, e, g, 1, o and q, might probably be linked to species recognition in $B$. germanica, whereas strain recognition might be linked to the more variable part (dimethylalkanes). Although we were not able to demonstrate this point, only very small quantitative differences in a few components are probably sufficient to induce strain discrimination. The exact manner in which recognition occurs in B. germanica strains remains to be clarified. The problem of designing good bioassays suggests that most of these chemicals might not be used by the insects for communication (Howard, 1993).

\section{REFERENCES}

Augustynowicz M.E., Malinski Z., Warnke J., Szafranek J. \& NAWrot J. 1987: Cuticular hydrocarbons of the German cockroach Blattella germanica L. Comp. Biochem. Physiol. 86: 519-523.

Bagnères A.G., Clément J.L., Blum M.S., Sevenson R.F., Joulie C. \& LANGE C. 1990: Cuticular hydrocarbons and defensive compounds of Reticulitermes flavipes (Kollar) and Reticulitermes santonensis (Feytaud): polymorphism and chemotaxonomy. J. Chem. Ecol. 16: 3213-3244.

Bagnères A.G., Killian A., Clément J.L. \& Lange C. 1991: Interspecific recognition among termites of the genus Reticulitermes: evidence for a role for the cuticular hydrocarbons. $J$. Chem. Ecol. 17: 2397-2420.

BenzeCri J.P. 1973: L'analyse des données. II - L'analyse des correspondances. Dunod, Paris, Fr., 619 pp.

Bonavita-Cougourdan A., Clément J.L. \& Lange C. 1987: Nestmate recognition. The role of cuticular hydrocarbons in the ant Camponotus vagus Scop. J. Entomol. Sci. 22: 1-10.

Bonavita-Cougourdan A., Clément J.L. \& Lange C. 1989: The role of cuticular hydrocarbons in recognition of larvae by workers of the ant Camponotus vagus: changes in the chemical signature in response to social environment (Hymenoptera: Formicidae). Sociobiology 16: 49-74

Brown W.V., Watson J.A.L., Lacey M.J., Morton R. \& Miller L.R. 1996: Composition of cuticular hydrocarbons in the Australian harvester termite Drepanotermes perniger (Isoptera: Termitidae): variation among individuals, castes, colonies and locations. Sociobiology 27: 81-197.

CARLSON D.A. \& BRENNER R.J. 1988: Hydrocarbon-based discrimination of three North American Blattella cockroach species (Orthoptera: Blattellidae) using gas chromatography. Ann. Entomol. Soc. Am. 81: 711-723.

Clément J.L. 1986: Open and closed societies in termites of the genus Reticulitermes, geographic variations and seasonality. Sociobiology 11: 311-323.

Cloarec A., Rivault C. \& Cariou M.L. 1999: Genetic population structure of the German cockroach, Blattella germanica: absence of geographical variation. Entomol. Exp. Appl. 92: 311-319

Dafri A. \& Lenor A. 1998: Nest separation and the dynamics of the Gestalt odour in the polydomous ant Cataglyphis iberica (Hymenoptera: Formicidae). Behav. Ecol. Sociobiol. 42: $349-355$.

De Renobales M., Nelson D.R. \& Blomquist G.I. 1991: Cuticular lipids. In: Binnington K. \& Retnakaran A. (eds), Physiology of the Insect Epidermis. CSIRO Publications, East Melbourne, Victoria, Australia, pp 240-251.

Fenelon J.P. 1981: Qu'est ce que l'analyse des données? Lefonen, Paris, 331pp.

GreEnACRE M.J. 1984: Theory and Applications of Correspondance Analysis. Academic Press, London. 357 pp.

HOWARD R.W. 1993: Cuticular hydrocarbons and chemical communication. In: Stanley-Samuelson D.W. \& Nelson D.R. (eds), Insect Lipids: Chemistry, Biochemistry and Biology, University of Nebraska Press, Lincoln, pp 179-226.

Jambu M. \& Lebeaux M.O. 1983: Cluster Analysis and Data Analysis. North-Holland Publishing Company, Amsterdam, $880 \mathrm{pp}$.

Jurenka R.A., Schal C., Burns E., Chase J. \& Blomquist G.J. 1989: Structural correlation between cuticular hydrocarbons and female contact sex pheromone of German cockroach Blattella germanica L. J. Chem. Ecol. 15: 939-949.

Nowbahari E., Lenoir A., Clement J.L., Lange G., Bagnères A.G. \& Joulie C. 1990: Individual geographical and experimental variation of cuticular hydrocarbon of the ant Cataglyphis cursor (Hymenoptera: Formicidae): their use in the nest and subspecies recognition. Biochem. Syst. Ecol. 18: 63-73.

Pasquet A., Trabalon M., Bagnères A.G. \& Leborgne R. 1997: Does group closure exist in the social spider Anelosimus eximius? Behavioural and chemical approach. Insectes Soc. 44: 159-169.

Provost E., Rivière G., Roux M., Morgan E.D. \& Bagnères A.G. 1993: Change in the chemical signature of the ant Leptothorax lichtensteini Bondroit with time. Insect Biochem. Mol. Biol. 23: 945-957.

Rivault C. \& Cloarec A. 1995: Limits of insecticide cockroach control in council flats in France. J. Environ. Management 45: 379-393.

Rivault C. \& Cloarec A. 1998: Cockroach aggregation: discrimination between strain odours in Blattella germanica. Anim. Behav. 55: 177-84.

Rivault C. \& Cloarec A. 1999: Agrégation et discrimination entre souches chez Blattella germanica (L.) Dictyoptera: Blattellidae). Ann. Soc. Entomol. Fr. 35: 169-74.

Rivault C., Cloarec A. \& Sreng L. 1998: Cuticular extracts inducing aggregation in the German cockroach, Blattella germanica (L.). J. Insect Physiol. 44: 909-918.

Schal C., Burns E.L. \& Blomquist G.J. 1990a: Endocrine regulation of female contact sex pheromone production in the German cockroach, Blattella germanica. Physiol. Entomol. 15: 81-91.

Schal C., Burns E.L., Jurenka A. \& Blomquist G.J. 1990b: A new component of the female sex pheromone of Blattella germanica (L.) (Dictyoptera: Blattellidae) and interaction with other pheromone components. J. Chem. Ecol. 16: 1997-2008.

Vauchot B., Provost E., Bagnères A.G. \& Clément J.L. 1996: Regulation of the chemical signatures of two termite species Reticulitermes santonensis and R. (1.) grassei, living in mixed colonies. J. Insect Physiol. 42: 309-321.

Received February 4, 2002; revised April 23, 2002; accepted June 12, 2002 